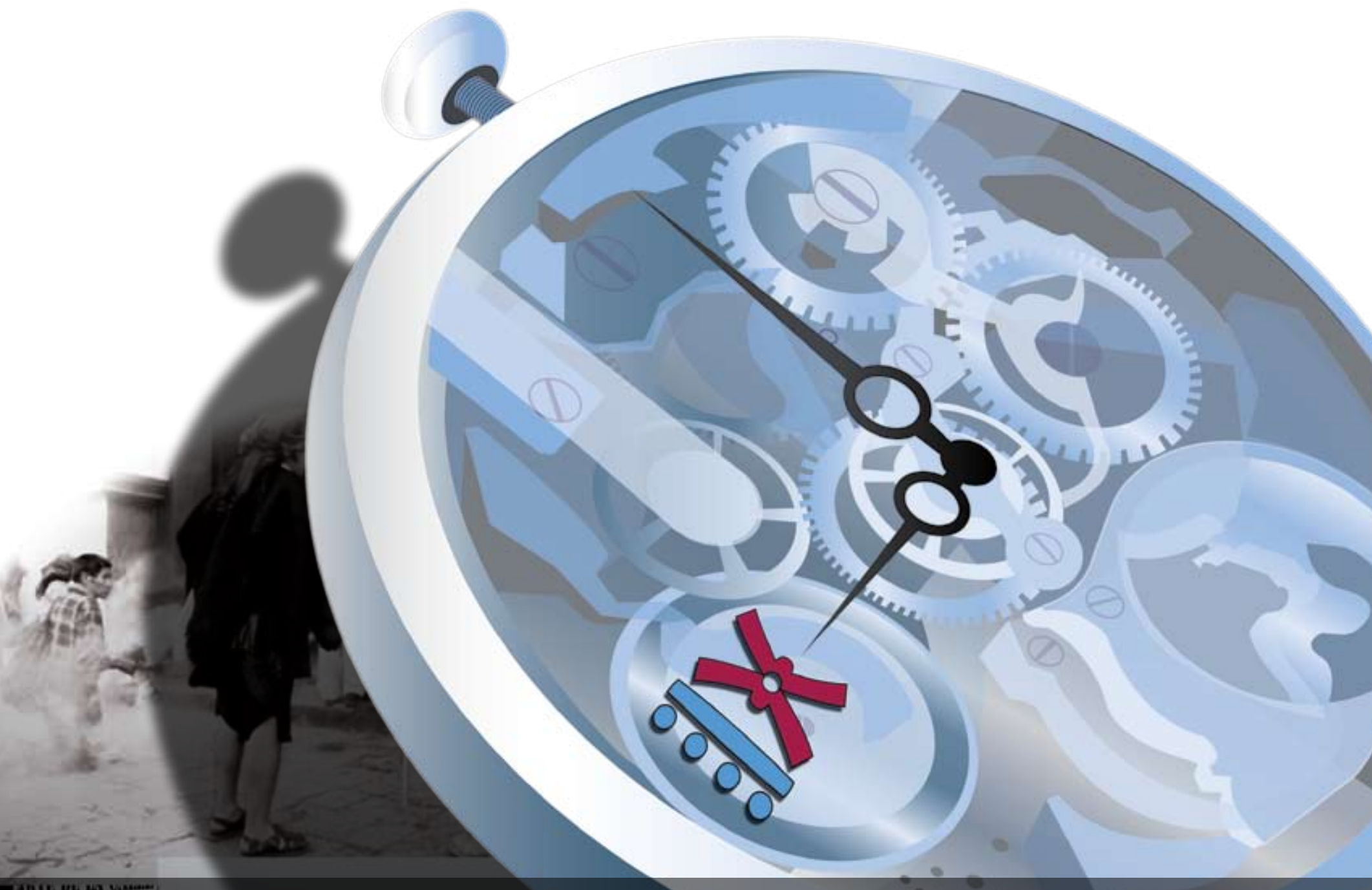

$\neg 9^{\circ}$ CONGRESO Q 2 CENTROAMERICANO DE HISTORIA
ISSN 1409-469X

Fecha de recepción: 15 de mayo 2008 Fecha de aceptación: 30 de mayo 2008

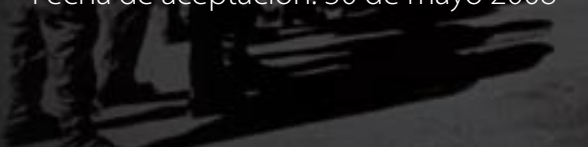

Encubrimiento Histórico de la violencia contra la mujer centroamericana

Miembros del Consejo Editorial:

Dr. Ronny Viales, Dr. Juan José Marín

Editores Técnicos:

Allan Fonseca, Andrés Cruz, Gabriela Soto
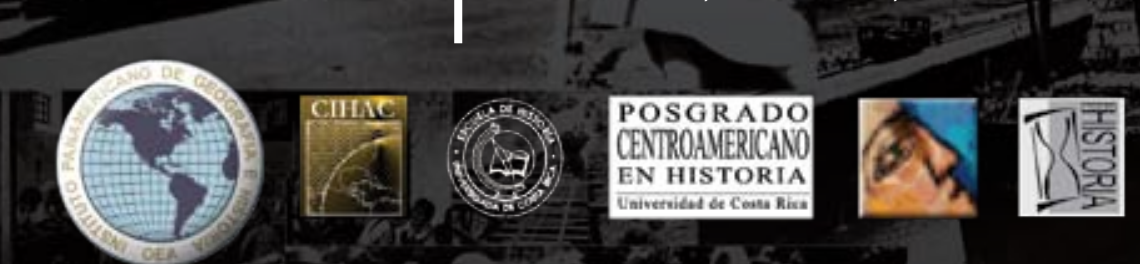
Indexaciones: Repositorio de Revistas UCR, DIALNET, Latindex, REDALYC Directorio y recolector de recursos digitales del Ministerio de Cultura de España, Directory of Open Access Journals. Diálogos Revista Electrónica de Historia ISSN 1409-469X. Número especial 2008. Dirección web: http://historia.fcs.ucr.ac.cr/dialogos.htm

\section{Encubrimiento Histórico de la violencia contra la mujer centroamericana}

Licda. Ileana Patricia Valdez Ochoa

Ciudad de Guatemala, Guatemala Tel. 502-53004451 Fax. 24760050

ileanavaldezo@yahoo.com 


\section{ENCUBRIMIENTO HISTORICO DE LA VIOLENCIA CONTRA LA MUJER CENTROAMERICANA}

Por: Licda. Ileana Patricia Valdez Ochoa*1

Cuando se inicia el estudio del porque se da el la violencia y el feminicidio en nuestra sociedad debemos de buscar respuestas, primero definiremos lo que es violencia. Violencia: Calidad de violento. Acción de violentar. Acción violenta o contra natural modo de proceder. Acción de violar o forzar a una mujer. ${ }^{2}$ Situación o estado contrario a naturaleza, modo o índole. Empleo de la fuerza para arrancar el consentimiento. Ejecución forzosa de algo, con independencia de su legalidad o ilicitud. Coacción para que alguien haga aquello que no quiere, o se abstenga de lo que sin ella se querría o se podría hacer. Presión moral. Opresión, fuerza. Violación de mujer $^{3}$

La primera interrogante que nos llega a la mente es ¿quien es el agresor de las mujeres? En primera instancia encontramos que son las parejas, compañeros íntimos, de las victimas. Personas que cuentan con la confianza de las victimas. Por otro lado se visualiza que los familiares también forman parte de la lista de agresores. (Hermanos, padres, hijos, etc.)

Por lo que es necesario señalar que las mujeres somos blanco de:

Odio Racial: Aversión, aborrecimiento. Sentimientos que trasciende al derecho de impulsos criminales, en fallos parciales, en relaciones inicuas, en antagonismos sociales, en

1 Licenciada en Historia, Profesora en Enseñanza Media en Historia y Ciencias Sociales, Técnico Universitario en Archivos, y Licenciada en Relaciones Internacionales (inf.). Egresada de la Universidad de San Carlos de Guatemala. Investigadora de Paz Editores, Catedrática de Historia Contemporánea de la Universidad Rafael Landivar.

2 CABANELLAS. Pág. 1047

3 OSORIO. Pág. 715 
desencadenamientos bélicos. ${ }^{4}$

\section{o Maltrato Machista}

o Relacionesdesiguales: Relaciones:Vinculo. Correspondenciaal actuar. Conexión. Trato. Comunicación. Analogía, semejanza. Relato, narración. ${ }^{5}$ Desigual: No igual inconstante. Adelantarse, aventajarse. Con fuerzas desproporcionadas en ataques o agresiones. Injusto-inicuo. Privilegio o favoritismo. En beneficio de unos o injusticia y desamparo con otros. ${ }^{6}$

o Discriminación: Discriminación: Separar, distinguir, diferenciar. Diferencia, diferenciación o desigualdad. ${ }^{7}$

o Objeto sexual: Cualquier cosa que se percibe por los sentidos. Relativo al sexo. Condición orgánica que distingue al hombre de la mujer. ${ }^{8}$

o La ven como objeto sexual - la mayor victima (la Primera)

\section{A. Aspectos Sociales:}

Provocados por la descomposición familiar, y vicios en la sociedad como drogadicción, alcoholismo, prostitución y otros.

- Características no propias de las mujeres:

0 Inseguridad

o Pasividad

o Indecisión

$4 \quad$ OSORIO Pág. 510

5 Idem Pag. 600

6 Íbidem. Pág. 661

7 Idem Pág. 737

8 Ibidem Pag. 1500 
o Falta de respuesta a la agresión

o Silencio

o Perdida de autoestima

o Introversión

o Resistencias a expresar sentimientos

o Desconfianza general

\section{B. Aspectos Económicos:}

Somos utilizadas como empleadas de segunda categoría por los salarios bajos, y otros, etc. Más sin embargo somos las que aportamos en un $100 \%$ del dinero que se gana para la familia.

- Bajos Salarios

- Sin horarios fijos

- Sin Sueldo

- Trabajo de tiempo parcial

- Trabajos Temporales

- Pobreza Extrema

- Vida deshumana

- Efectos de estos problemas:

- Afecta la Relación Familiar y por ende Sociedad:

- Se afecta la Producción y Reproducción:

- Se afecta la procreación y crianza de niños:

\section{Aspectos de Salud:}

En salud no hay centros especializados en el cuidado de la salud de la mujer, y el presupuesto de la nación no contempla un rubro específico para ello, y si en algún momento se canaliza no 
llega a su destino.

- Sin servicios de salud

- Mala alimentación

- Sin seguro social.

\section{Motivos por los cuales las mujeres somos maltratadas:}

Motivos reales no hay pero entre los supuestos motivos por los que se dan son:

o Exclusión: Exclusión: Separación de la persona o cosa del grupo o clase a que pertenece. Prohibición cuando de disposiciones permisivas se trata. Negación de una posibilidad, excepción (desheredación, excluir, inclusión, pretensión.). ${ }^{9}$

o Descalificación: Exclusión en una actividad o postergación en los ascensos o recompensas por evidente ineptitud o mala conducta. ${ }^{10}$

o Segregación: Segregación: Acto proceso, estado social, establece que puede ser consecuencia de la ley, como en las escuelas para gente de raza desdeñada, por la costumbre social, pasajeras como en ciertos ostracismos temporales; o empleo de fuerza en casos urgentes. ${ }^{11}$

o Relaciones enfermas: Relaciones: Vinculo. Correspondencia al actuar. Conexión. Trato. Comunicación. Analogía, semejanza. Relato, narración. ${ }^{12}$ Enfermo: Quien sufre o padece una enfermedad de no provocar invalidez completa o significar grave alteración de las dificultades mentales, el enfermo conserva su capacidad jurídica normal, con fundada excusa por tal causa para

9 CABANELLAS Pág. 275

10 Ídem. Pág. 637

11 OSORIO, Manuel_Pag. 620

12 Idem Pag. 600 
ciertas obligaciones personales, y con expresos derechos en materia laboral. ${ }^{13}$

o Relaciones Incompletas: Incompleto: Falta de algo. De conocimiento incompleto. ${ }^{14}$

o Relaciones destructivas Destructivo: Se aplica a lo que tiene poder, Facultad o medio para destruir. ${ }^{15}$

o Inexistencia Legal: Inexistencia (Legal): Carencia Falta. La inexistencia es el grado máximo de la ineficacia en los negocios jurídicos, que no se han producido o que no pasan de una mera apariencia, en el encubrimiento del fraude o en la forma equivoca de la simulación. ${ }^{16}$

Entre estos hay mujeres que no existen para los registros del país ya que no cuentan con acta de nacimiento. Por haber nacido en el altiplano del país

\section{E. Como se puede evitar este tipo de problemas:}

o Denunciarlo: Denuncia: (Derecho procesal penal) Es la manifestación que se hace ante la autoridad, o juez, del conocimiento que se tenga de la perpetración de cualquier delito o falta de que lugar o la acción penal pública. ${ }^{17}$

o Señalarlo (Señalar: Identificar en un grupo.)

o No dejarlo pasar: Dejar: Soltar algo. Retirarse o apartarse de una cosa, lugar o puesto. Interrumpir, cesar. ${ }^{18}$

o Actuar en consecuencia: Actuar: Ejercer una persona o cosa las facultades propias de la misma. Poner en acción. Abandonar la pasividad y adoptar una actitud, ante una

13 Ibidem Pág. 113

14 Ídem. Pág. 684

15 Ibidem. Pág. 684

16 Ídem. Pág. 710

17 Ibidem. Pág. 551

18 Ídem. Pág. 518 
situación o conflicto. ${ }^{19}$

o Decirlo: Decir: Manifestación o declaración verbal. ${ }^{20}$

Transformarlo: Transformar: Cambiar sensiblemente a una persona, cosa o situación. Hacer con materia ajena un trabajo propio. Convertir una cosa en otra. ${ }^{21}$

Lo lamentable del asunto es que en nuestro país se cuenta con entidades que respalden a las victimas, pero las leyes no son suficientes ya, puesto que al pedir "orden de alejamiento", o "restricción" no se llega a concretar ya que la pareja tanto el victimario como la victima viven en la misma casa y comparten la habitación. Como el caso de Blanca Prado quien manifestó "Un papel no me defiende de los golpes de mi marido, mejor me hubieran dado una pistola". Dado a que se toma 30 minutos en aparecer una patrulla después de esperar 10 minutos esperando y escuchar la contestadora, con el mensaje de "su llamada es muy importante para nosotros, espere en línea, en este momento estamos atendiendo otros llamados..." Alejamiento: (Alejar) Situar mas allá. Excluir de una actividad hasta entonces desempeñada, sea por incompetencia por motivos bastardos. Disipar un peligro o superar un riesgo. Alejamiento: Acción o efecto de alejar o de alejarse. ${ }^{22}$ Restricción: Limitación. Disminución de facultades o derechos. Escasez o rebaja en la provisión de ciertos productos o alimentos. ${ }^{23}$

Ya que al llamar a la seguridad publica se llevaban al agresor y en dos días sale libre de la cárcel y vuelta a la casa. (Ver Grafica No. 1)

- Falta de educación: y el entorno obligan a la mujer a supeditarse al hombre.

- Con el desarrollo de la política:

19 Ibidem. Pág. 149

20 Ídem. Pág. 491

21 CABANELLAS Pág. 495

22 OSORIO. Pág. 244

23 CABANELLAS. Pág. 751 
- La Cultura

- Las Ideas

- La tradición

Aunque se actúe en los altos niveles de nuestro país, si se quiere o utilizar la ley para defenderse son llamadas las mujeres "PUTAS, LESVIANAS, Y FEMINISTAS” de eso no se libra ninguna mujer, no importando su clase social.

El patriarcado o machismo imperante aun sigue en peor Siglo XXI haciendo estragos a la comunidad femenina. Lo peor del caso es que va en aumento.

\section{- Análisis de Graficas}

Es importante observar las graficas que muestran los casos de feminicidios en nuestro país.

La edad que ha sido golpeado con este problema es de 21 a 25 años, son mujeres jóvenes, en edad productiva y reproductiva, con niños menores de 10 años, los que quedan en la orfandad, puesto que el padre huye de la responsabilidad o cuando se le encuentra culpable pues estará en la cárcel por asesinato a su pareja. (Ver Grafica No. 2)

Los días que mas suceden estos casos son el día domingo, puesto que es el día de descanso en el área laboral, y muchos se dedican al ocio, o dan rienda suelta a la satisfacción de los vicios, por lo que no atienden a la familia y se dan discusiones entre parejas por cualquier tipo de razón. (Ver Grafica No. 3)

Las muertes se dan en su mayor porcentaje por arma de fuego. Las personas que portan arma son: por autorización por la DECAM, o las que laboran con la seguridad publica o la delincuencia o los narcotraficantes que compran armas en el mercado negro. (Ver Grafica No. 4)

Como se había señalado esto va en aumento tan es así que el año 2,005 hubo 5,308 muertes y en el año 2,006 hubo 5,884. El aumento de año a año es de un 10.85\%, si esto se compara con años 
anteriores aumenta el porcentaje diferencial. (Ver Grafica No. 5)

Nuestro país cuenta con 22 departamentos, de los cuales 3 son los que muestran mayor índice por ejemplo el de Guatemala donde sen encuentra 17 municipios se registra un $41.81 \%$ de asesinatos este se encuentra en la región Metropolitana del país, lo que representa que es el área donde se concentran todas las transacciones comerciales del país. En Escuintla se registra un 8.06\% de asesinatos de mujeres este se encuentra en la costa sur del país a 30 grados de temperatura, a esto hay que agregar que se encuentra el Puerto de San José, Quetzal e Iztapa, los que se dedican a la transacción de mercancías, por lo que es muy visitado por extranjeros. En el Peten que se ubica al norte con 35 a 40 grados de temperatura donde se encuentra la reserva natural de Bosques, colinda con Belice y México, presenta un índice de 5.90\%. A estos registros habría que agregar las personas desaparecidas, que no se han encontrado sus cuerpos como evidencia de tales hechos.

\section{- Se debe de actuar en:}

o En el ámbito familiar

o En el ámbito Laboral

o En el ámbito Escolar

o En el ámbito comunitario

o En el ámbito partidario

o En el ámbito organizativo

Hoy la mujer esta cansada de aguantar la bota infiel, déspota y cruel masculina, por lo que hacen saber su situación ante las entidades de derechos humanos. Otras aun siguen sufriendo en silencio los golpes, y sufrir la ineficacia de la ley, que solo queda en el papel y no hay un acto de protección para que no siga repitiendo este triste cuadro. 


\section{- El Terror produce:}

o Siembra miedo

o Daños físicos, golpes y muerte.

o Atemorización de las mujeres

o Tortura psicológica

o Menosprecio

o Practicas vejatorias

o Abuso sexual

o Sesgo sexista

o Imposición

o Atemorización familiar y social que las rodea.

o Ideología de Inspiración Política

o Asignación Filosófica - Social

o Político -sexista

o Político-religiosa

o Radicalidad: Promueve actos delictivos

- Mujeres Centroamericanas del siglo XX que han sido victimas de violencia

Blanca Mora y Araujo: Esposa de Miguel Ángel Asturias, sufrió el alcoholismo de su esposo. $^{24}$ (Ver Fotografía No1)

La Tatuana: fue una mujer que tuvo realidad física. Se le menciona tanto durante el largo período de la dominación española, como en la época de los 30 años en el siglo XIX.

Afirma la tradición que La Tatuana fue una bruja condenada por la Inquisición a ser quemada viva en la Plaza Mayor de Santiago de Guatemala. Prendida por orden del Capitán General y 24 www.prensalibre.com.gt 
encerrada en una bartolina, "La Tatuana pidió una gracia: que le fuera entregado un pedacito de carbón. Así lo hicieron los soldados. Al tener en sus manos el trozo de carbón, dibujó en la pared un barquito, se subió en él y voló por entre los barrotes. ${ }^{25}$ (Ver Fotografía No. 2)

Joaquina Cabrera: (La oblitera) Madre de Manuel Estrada Cabrera fue discriminada por dedicarse ha hacer bolitas de tamarindo para la manutención de su hijo.

Punto histórico es la avenida "Reforma" donde se encuentra actualmente la sede del Ministerio de Educación que, a principios del siglo pasado, fue la sede del Asilo Joaquina (foto), nombre de la madre de Manuel Estrada Cabrera, uno de los dictadores que más duraron en el $\operatorname{poder}^{26}(20$ años) (Ver Fotografía No. 3)

Manuel Estrada Cabrera tuvo en total 14 hijos reconocidos: 7 varones y 7 mujeres.

Desideria Ocampo: Esposa de Manuel Estrada Cabrera, nunca se exhibió con su esposo del brazo en actos públicos, fue sumida a su casa de habitación para oficios domésticos. ${ }^{27}$ (Para lo que supuestamente estaban destinadas las mujeres) (Ver Fotografía No.4)

Maria Chinchilla Recinos: Maestra asesinada por la Policía montada en la 17 calle y $6^{\mathrm{a}}$. Ave. Zona 1 en la manifestación de Mujeres Enlutadas del 25 de Junio de 1,944 contra la dictadura de Jorge Ubico Castañeda. ${ }^{28}$ (Por luchar por los derechos magisteriales) (Ver Fotografía No. 5)

Nineth Montenegro: El 18 de febrero de 1984, Fernando García, esposo de Nineth Montenegro, fue secuestrado por agentes del Estado. García era asesor de la Escuela de Orientación Sindical y estudiante de Ingeniería, además era sindicalista de Cavisa. Ello motivó 25 Idem.

26 Ibidem.

27 Idem.

28 VALDEZ OCHOA, Ileana Tesis de Historiadora Asociaciones femeninas durante el Gobierno del General Ubico Castañeda. (Caso Maria Chinchilla) 
a Montenegro de García a fundar el GAM. ${ }^{29}$ (Ver Fotografía No. 6)

Rigoberta Menchú: Premio Nóbel de la Paz de 1992, los seguidores del FRG la insultaron en 2003: “Me decían 'india sucia, hija de..., andá a vender tomates a La Terminal’, eso le marcó porque demuestra lo lejos que estamos de que en este país todos seamos tratados por igual". Quien perdió a su padre en la quema de la embajada de España. (Ver Fotografía No. 7)

Violeta Barrios de Chamorro: Su esposo fue Pedro Joaquín Chamorro Cardenal quien fue encarcelado y después asesinado por el Dictador Anastasio Somoza García el 10 de enero de 1,978. Dejo su hogar por tomar el lugar de su esposo en la dirigencia del Diario La Prensa. Política, Periodista nicaragüense, Presidenta de Nicaragua de 1,990 a 1,997. ${ }^{30}$ (Ver Fotografías No.8 y 9 )

Aguas Ocaña de Maduro: española casada con el Presidente de Honduras con Ricardo Maduro. Aguas realizó obras sociales con los niños y adolescentes en situación de riesgo, con problemas de violencia domestica, abuso sexual, y explotación, su trabajo fue ayudar al mas necesitado por lo que obtuvo mas popularidad que el Presidente. Se divorció de Ricardo Maduro tras el engaño con la Ministra de Cultura, Artes y Deportes Mireya Batres, quien fue su novia previo a asumir la Magistratura.

Además los medios escritos hondureños no respetaron la posición de la Primera dama tras la difamación que le hiciera la Columna "Pildoritas de La Tribuna" diciéndole "mentirosa" a viva voz en una reunión navideña. (Su esposo jamás le dio el lugar de Esposa ni Primera dama, irrespetándola como mujer y como funcionaria) ${ }^{31}$ (Ver Fotografía No. 10)

$29 \quad$ www.prensalibre.com.gt

30 www.prensalibre.com.gt. Violeta Chamorro: Presidenta por herencia.

31 www.prensalibre.com.gt Aguas Ocaña ya está en Nicaragua. 


\section{CONCLUSIONES}

1. No hay ley que logre una verdadera y efectiva protección a la mujer centroamericana contra todo tipo de la violencia.

2. La violencia nace crece y se reproduce dentro de los hogares centroamericanos.

3. Ninguna mujer no importa raza, profesión, clase social, ni nacionalidad se encuentra ajena a la violencia. Esta se da por la reproducción del Patriarcado y Machismo imperante que las mismas mujeres nos encargamos de reproducir e imponer.

4. Basta solo el hecho de ser mujer para ser blanco de la violencia en general.

5. En casos de violencia se debe de denunciarlo, publicarlos y decirlo a las autoridades.

6. No hay cuerpo de seguridad suficiente y eficaz que pueda lograr prevenir estos tipos de violencia ya que en muchos países latinoamericanos se observa como parte de la vida cotidiana.

7. La historia ha sido encubridora de la Violencia contra la Mujer en General, es el caso de Centroamérica, la ha llamado Conflicto Armado Interno.

8. Hoy la historia ya no puede seguir encubriendo este gran problema llamándole Violencia Generalizada provocada por la pobreza extrema, hambre que muchos de nuestros pueblos atraviesan.

9. Lo lamentable del asunto que muchos cientistas sociales llamándose así mismas feministas piensan que es un problema nuevo surgido del Liberalización femenina declarada en los años 60s en Estados Unidos de América. Lo que no es cierto comprobado y expuesto en esta ponencia.

10. La Violencia através de la historia se le ha llamado de diferentes formas, pero al final de cuentas es VIOLENCIA DE GÉNERO. 


\section{BIBLIOGRAFIA}

1. PROCURADORIA DE LOS DERECHOS HUMANOS P.D.H Graficas del informe sobre el Feminicidio en Guatemala. Folleto. 20 Paginas.

2. TENDENCIA DEMOCRATICA REVOLUCIONARIA. Ejercito del Pueblo 8 de Marzo: Día de la Indignación e insurgencia Femenina ¿Calladita te ves mas bonita? 2 Páginas. Comunicado.

3. ARMAOLEA, Odei Mujer, Consumo y Revolución. 4 Paginas. Folleto.

4. CABAnELlaS, Guillermo Diccionario Enciclopédico de Derecho Usual. Tomo I-X. 12a . Edición. Editorial Heliasta S.R.L. Buenos Aires, Argentina.

5. ESCOBAR SARTI, Carolina Nacen 20 Mil Mujeres 2 Paginas. Artículo.

6. OSORIO, Manuel Diccionario de Ciencias Jurídicas Políticas y Sociales Editorial Heliasta S.R.L. Viamonte 1,730. Buenos Aires Argentina 1,987

7. ESPASA CALPE Diccionario Jurídico Espasa Fundación Tomas Moro. Madrid. 1,991.

8. SANDRASAGRA, Mithre J. Trafico Incesante de Mujeres. 2 Paginas.

9. SORIANO DIAZ, Ramón,

ALARCON CABRERA, Carlos, MORA MOLINA, Juan Diccionario Crítico de los Derechos Humanos. Estado en España. 1era Edición. Universidad Internacional de Andalucía Sede Iberoamericana 2,000 .

10. VALDEZ OCHOA, Ileana Asociaciones Femeninas durante el Gobierno del General Jorge Ubico Castañeda (Caso Maria Chinchilla) Tesis de Historiadora. 


\section{ONO $9^{\circ}$ CONGRESO \\ - 8 CENTROAMERICANO \\ U DE HISTORIA \\ Universidad de costa Rice}

Indexaciones: Repositorio de Revistas UCR, DIALNET, Latindex, REDALYC Directorio y recolector de recursos digitales del Ministerio de Cultura de España, Directory of Open Access Journals. Diálogos Revista Electrónica de Historia ISSN 1409-469X. Número especial 2008. Dirección web: http://historia.fcs.ucr.ac.cr/dialogos.htm

11. VAN OSDOL, JUDITH En el Día Internacional de la Mujer. 1 Pagina. Pastoral de las Mujeres y Género.

12. www.prensalibre.com.gt 
Indexaciones: Repositorio de Revistas UCR, DIALNET, Latindex, REDALYC Directorio y recolector de recursos digitales del Ministerio de Cultura de España, Directory of Open Access Journals. Diálogos Revista Electrónica de Historia ISSN 1409-469X. Número especial 2008. Dirección web: http://historia.fcs.ucr.ac.cr/dialogos.htm

\section{GRAFICAS}

GRAFICA No. 1

Violencia contra mujeres según forma de muerte, 2006

\section{En porcentaje}

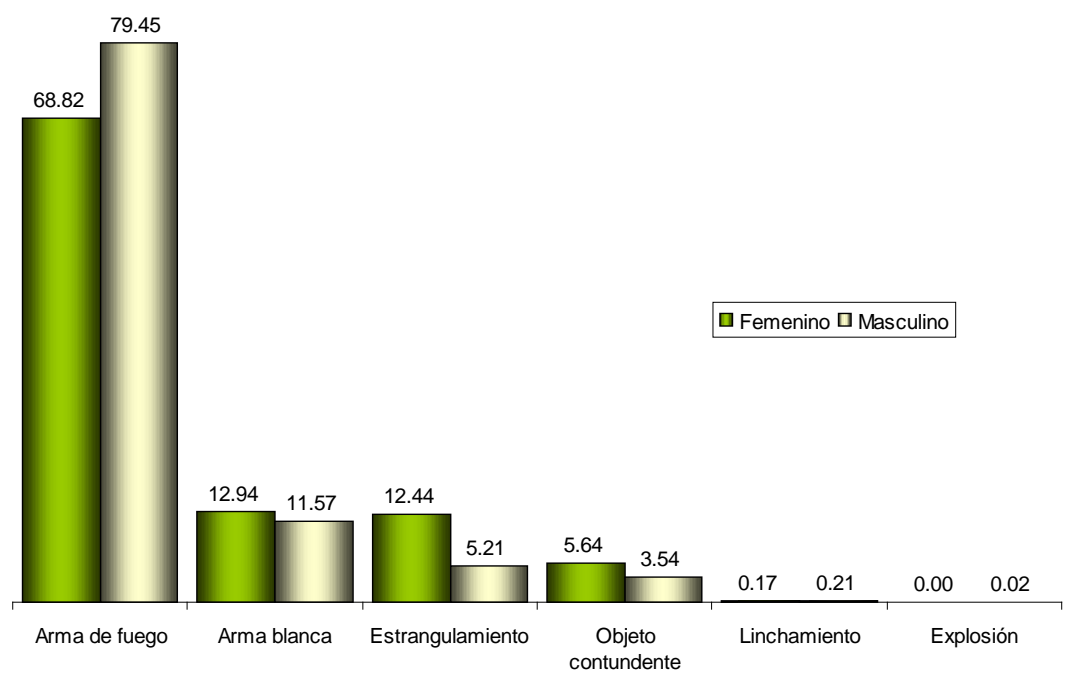

Fuente: Elaboración Propia PDH, UEA 


\section{O $19^{\circ}$ CONGRESO \\ O $\$$ CENTROAMERICANO \\ DE HISTORIA \\ Universidad de costa Rica}

Indexaciones: Repositorio de Revistas UCR, DIALNET, Latindex, REDALYC Directorio y recolector de recursos digitales del Ministerio de Cultura de España, Directory of Open Access Journals. Diálogos Revista Electrónica de Historia ISSN 1409-469X. Número especial 2008. Dirección web: http://historia.fcs.ucr.ac.cr/dialogos.htm

\section{GRAFICA No. 2}

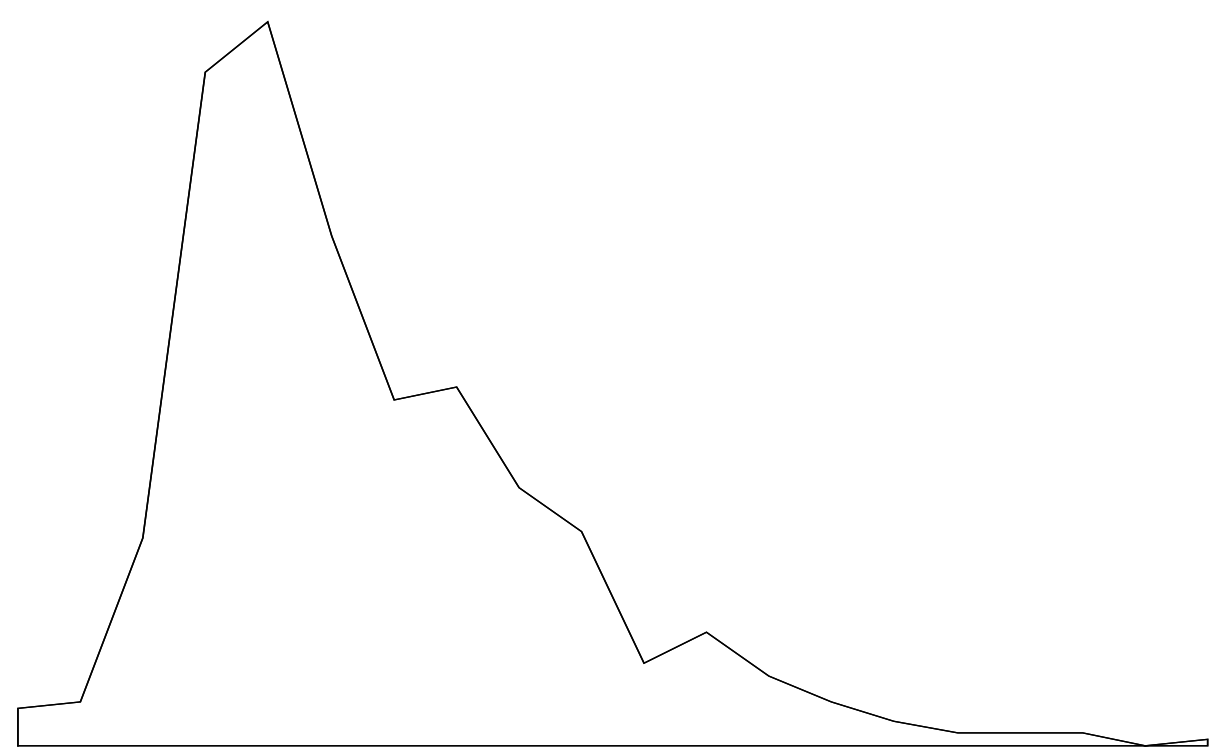

Fuente: Elaboración Propia PDH, UEA 
Indexaciones: Repositorio de Revistas UCR, DIALNET, Latindex, REDALYC Directorio y recolector de recursos digitales del Ministerio de Cultura de España, Directory of Open Access Journals.

\section{GRAFICA No. 3}

\section{Muerte violenta de mujeres y violencia intrafamiliar}

según el día en que ocurre el hecho, 2006

\section{En porcentaje}

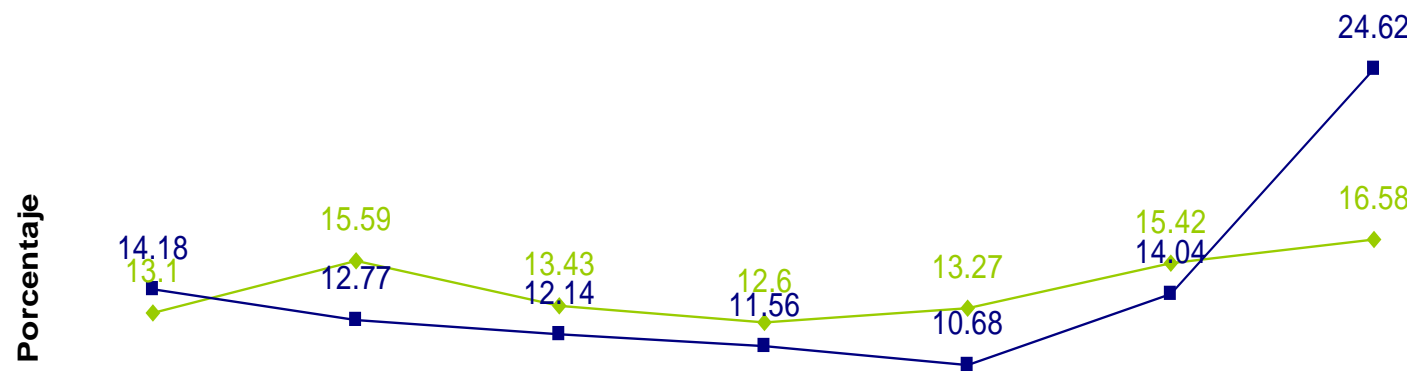

\begin{tabular}{|c|c|c|c|c|c|c|}
\hline Lunes & Martes & Miércoles & Jueves & Viernes & Sábado & Domingo \\
\hline
\end{tabular}

Fuente: Elaboración Propia PDH, UEA 
Indexaciones: Repositorio de Revistas UCR, DIALNET, Latindex, REDALYC Directorio y recolector de recursos digitales del Ministerio de Cultura de España, Directory of Open Access Journals.

\section{GRAFICA No. 4}

\section{Número de casos de homicidio, por año}

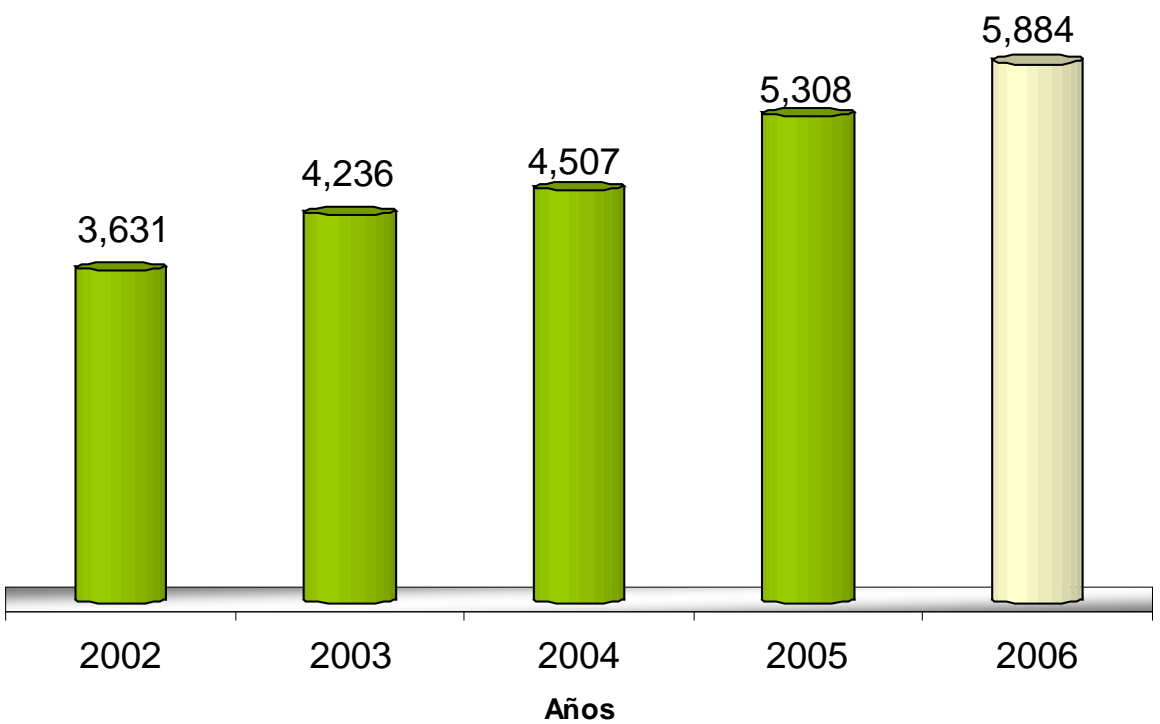

Fuente: Elaboración Propia PDH, UEA 
Indexaciones: Repositorio de Revistas UCR, DIALNET, Latindex, REDALYC Directorio y recolector de recursos digitales del Ministerio de Cultura de España, Directory of Open Access Journals. Diálogos Revista Electrónica de Historia ISSN 1409-469X. Número especial 2008. Dirección web: http://historia.fcs.ucr.ac.cr/dialogos.htm

\section{GRAFICA No. 5}

\section{Homicidios según departamento}

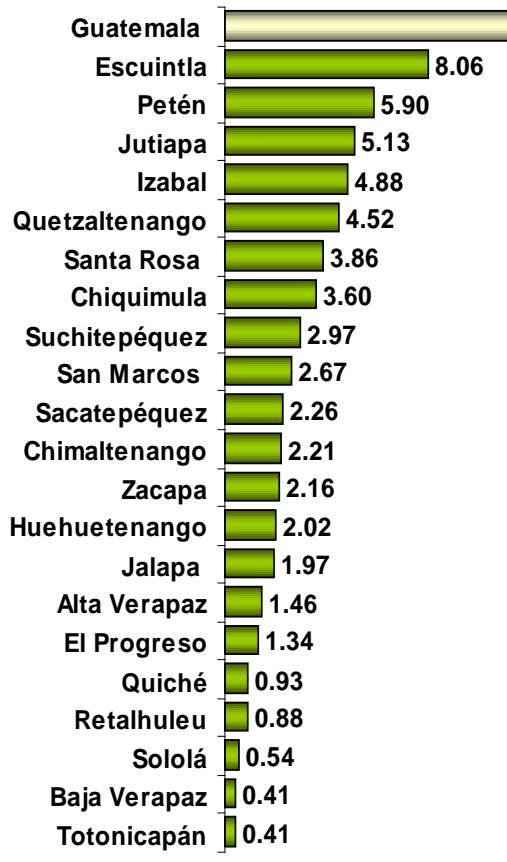


Indexaciones: Repositorio de Revistas UCR, DIALNET, Latindex, REDALYC Directorio y recolector de recursos digitales del Ministerio de Cultura de España, Directory of Open Access Journals. Diálogos Revista Electrónica de Historia ISSN 1409-469X. Número especial 2008. Dirección web: http://historia.fcs.ucr.ac.cr/dialogos.htm

\section{FOTOGRAFIAS}

Fotografía No. 1

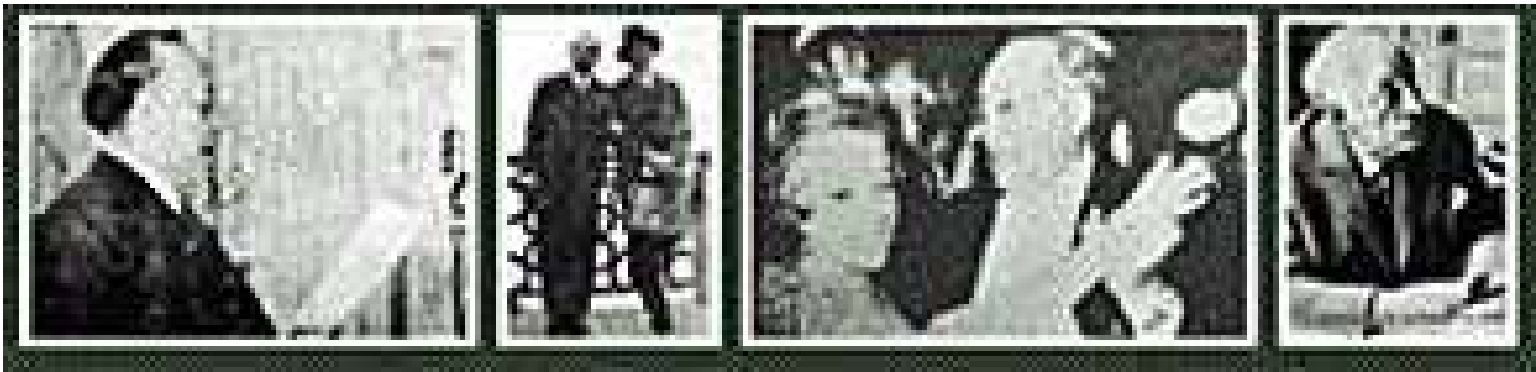

Fotografía No. 2

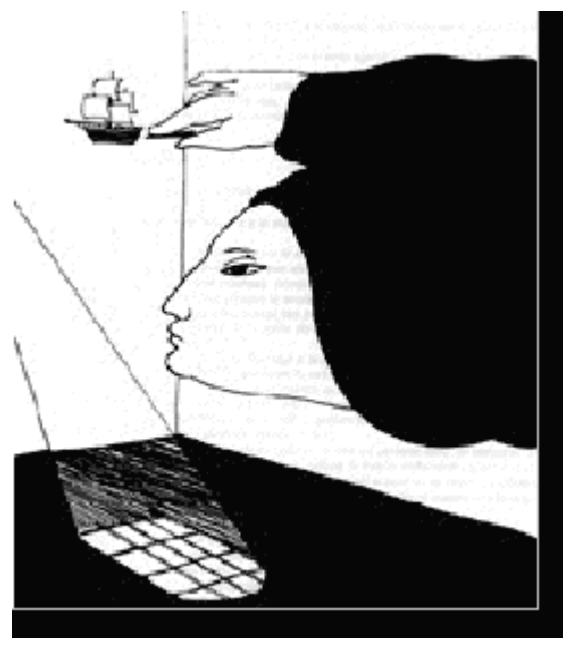




\section{of \\ of CENTROAMERICANO \\ DE HISTORIA}

Universidad de costa Rica

Indexaciones: Repositorio de Revistas UCR, DIALNET, Latindex, REDALYC Directorio y recolector de recursos digitales del Ministerio de Cultura de España, Directory of Open Access Journals.

Diálogos Revista Electrónica de Historia ISSN 1409- 469X. Número especial 2008. Dirección web: http://historia.fcs.ucr.ac.cr/dialogos.htm

Fotografía No. 3

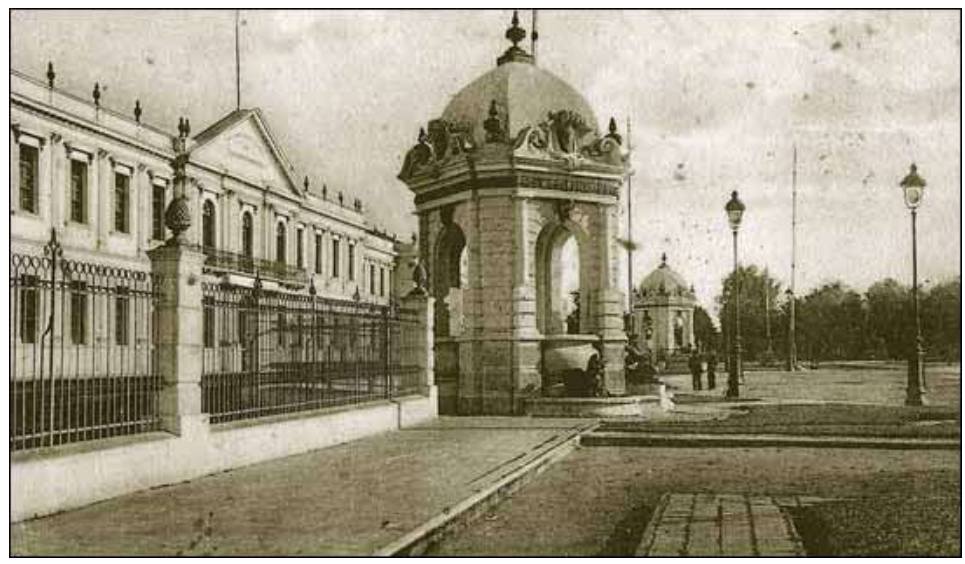

Fotografía No. 4

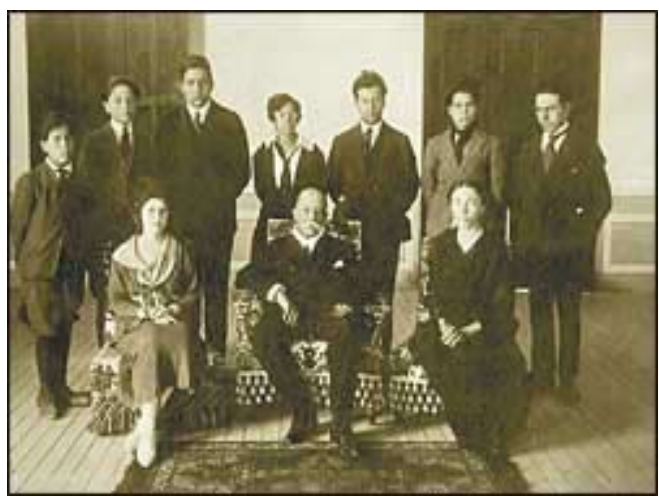




\section{OI $9^{\circ}$ CONGRESO \\ - $:$ CENTROAMERICANO \\ DE HISTORIA}

Universidad de costa Rica

Indexaciones: Repositorio de Revistas UCR, DIALNET, Latindex, REDALYC Directorio y recolector de recursos digitales del Ministerio de Cultura de España, Directory of Open Access Journals.

Diálogos Revista Electrónica de Historia ISSN 1409-469X. Número especial 2008. Dirección web: http://historia.fcs.ucr.ac.cr/dialogos.htm

\section{Fotografía No.5}

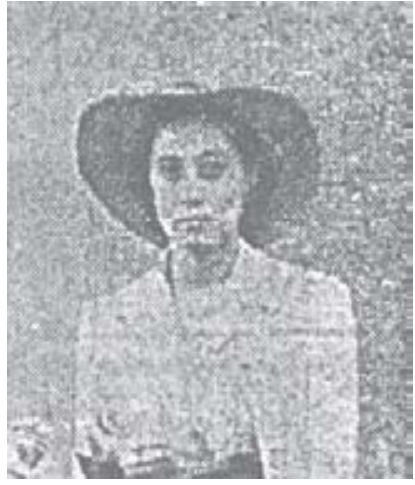

Maestra Maria Chinchilla Recinos

Fuente Imparcial Julio 1,944

Fotografía No. 6

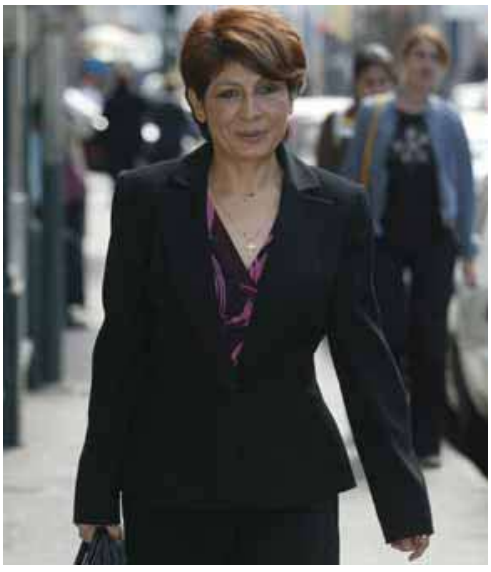




\section{ON $9^{\circ}$ CONGRESO \\ - $:$ CENTROAMERICANO \\ DE HISTORIA}

Universidad de costa Rica

Indexaciones: Repositorio de Revistas UCR, DIALNET, Latindex, REDALYC Directorio y recolector de recursos digitales del Ministerio de Cultura de España, Directory of Open Access Journals.

Diálogos Revista Electrónica de Historia ISSN 1409-469X. Número especial 2008. Dirección web: http://historia.fcs.ucr.ac.cr/dialogos.htm

Fotografía No. 7

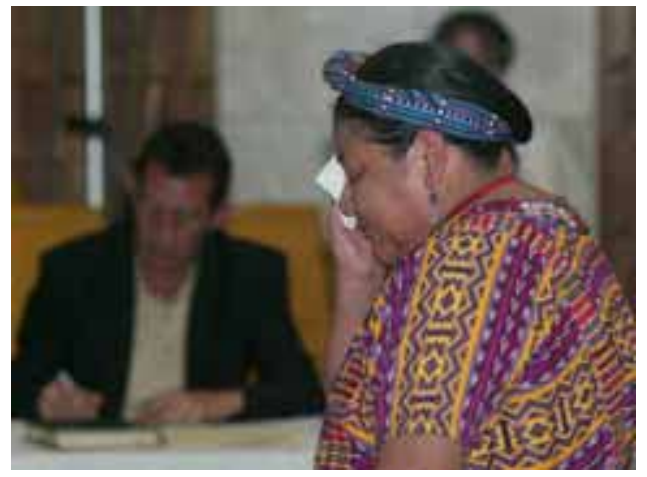

Fotografías No. 8 y 9
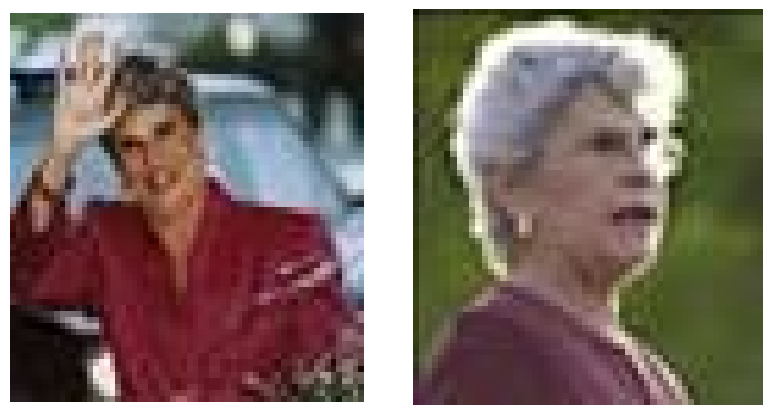

Fotografías No. 10

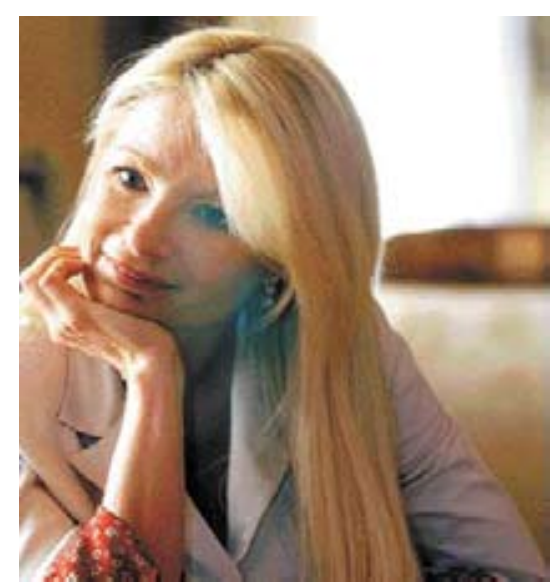

